\title{
Biopolítica e normatividade: duas abordagens filosóficas acerca da pandemia da Covid-19 a partir de Agamben e Habermas
}

\author{
Biopolitics and normativity: two philosophical approaches about the Covid-19 \\ pandemic from Agamben and Habermas
}

\section{Jozivan Guedes*}

Resumo: Este artigo analisa o problema da pandemia da Covid-19 do ponto de vista filosófico a partir dạs contribuições de Agamben e Habermas. Agamben aborda a dimensão biopolítica da pandemia e sugere que o isolamento social é uma estrategia política de exceção com vistas a limitar a liberdade das pessoas. Nesse sentido, ele fala em "invenção epidêmică". Habermas aborda a Covid-19 do ponto de vista normativo ponderando que as questões devem ser refletidas a partir da perspectiva ética da dignidade humana, e do ponto de vista político da solidariedade. A minha hipótese é a de que Agamben acerta em alguns pontos a sua análise, mas tem limites porque não levạ em consideração a dimensão biológiça da letalidade da Covid-19. A análise de Habermas é mais condizente com uma abordagem realisța do vírus porque subscreve as orientações científicas da Organização Mundial da Saude e reivindica o papel normativo dos direitos humanos nas decisões ético-políticas em decisões que buscam atenuar os impactos da pandemia

Palavras-chave: Covid-19; Biopolítica; Normatividade; Agamben; Habermas

\begin{abstract}
This paper analyzes the problem of the Covid-19 pandemic from a philosophical point of view from the contributions of Agamben and Habermas. Agamben addresses the biopolitical dimension of the pandemic and suggests that the social isolation is an exceptional political strategy aimed at limiting people's freedom. Thus, he speaks of "epidemic invention". Habermas approaches Covid-19 from a normative point of view considering that issues must be reflected from an ethical perspective of the human dignity, and from a political dimension of the solidarity. My hypothesis is that Agamben gets his analysis right on some points, but it has limits because it does not consider the biological dimension of Covid-19's lethality. Thereby, Habermas' analysis is more consistent with a realistic approach to the virus because it subscribes to the scientific guidelines of the World Health Organization and claims the normative role of human rights in ethical-political decisions that search to attenuate the pandemic impacts.
\end{abstract}

Keywords: Covid-19; Biopolitics; Normativity; Agamben; Habermas

\section{Introdução}

Em termos de reflexão filosófica, não há um modelo único, imutável e eterno que detenha a palavra final e absoluta acerca de problemas, seja qual for a sua natureza e a sua especificidade. $\mathrm{O}$ contrário disso seria a incorrência num dogmatismo e, consequentemente, a decretação do fim da reflexão filosófica e da crítica. Sob esse pressuposto, a minha ideia neste artigo consiste em analisar a pandemia ${ }^{1}$ da Covid-19 a partir das contribuições filosóficas de dois autores oriundos de modelos teóricos distintos e alternativos, mas com posições relevantes acerca desta pandemia que ora enfrentamos. De um lado, Agamben e sua análise biopolítica, de outro, Habermas e seu diagnóstico filosófico a partir do conceito normativo de direitos humanos e dignidade humana.

De Agamben analisarei seus textos que encetam a hipótese de uma "invenção epidêmica" baseada no isolamento social, no confinamento, na ideia de contágio, e na construção do pânico

\footnotetext{
${ }^{1}$ Sobre o alcance e o estatuto científico de uma pandemia, escreve Peter Doherty: "as infecções pandêmicas são, por definição, problemas globais que não pode ser tratado exclusivamente por estados-nação individuais. Epidemiologistas, estatísticos e outros profissionais que trabalham na Organização Mundial da Saúde (OMS) com sede em Genebra, Suíça, têm a responsabilidade de declarar se está ocorrendo ou não uma pandemia”. DOHERTY. Pandemics: What everyone needs to know, p. 43.
}

*Professor do Programa de Pós-Graduação em Filosofia da Universidade Federal do Piauí, Teresina, PI. E-mail: jozivan2008guedes@gmail.com ORCID: $\underline{\text { https://orcid.org/0000-0003-4483-8393 }}$ 
coletivo com vistas a estabelecer um estado de exceção como condição de normalidade. Sobre isso, apontarei possíveis acertos da leitura biopolítica de Agamben e seus possíveis limites, especificamente, o de que ele oblitera o arcabouço biológico da pandemia e prescinde de considerar dados científicos acerca da letalidade da Covid-19, sobretudo, em se tratando da Itália, um dos países mais afetados e sofridos com o vírus.

De Habermas analisarei as implicações ético-políticas da pandemia do coronavírus mediante a centralidade normativa dos direitos humanos. O autor toma por base a septuagenária Lei Fundamental da República Federal da Alemanha (Grundgetz für die Bundsrepublik Deutschland) outorgada e promulgada no pós-guerra, em especial o Art. 2 de acordo com o qual "todos têm o direito à vida e à integridade física" (Jeder hat das Recht auf Leben und körperliche Unversehrtheit).

Em nível ético, Habermas vê dois desafios, (i) o dilema que os médicos têm sobre quem deve viver e morrer, e (ii) o problema concreto de determinar o momento correto e adequado de interrupção do distanciamento social diante dos apelos dos componentes neoliberais inclusos na justificativa da interrupção. Em nível político, ele concebe a difícil conjuntura epidêmica como uma possibilidade de enfrentamento do modelo neoliberal e de supressão de políticas que reforçam esse modelo como único e definitivo.

Como desfecho da análise, Habermas acentua o cuidado a fim de que não haja a legitimação e subscrição de seguimentos populistas e extremistas que se aproveitem do momento de vulnerabilidade global. O ponto de culminância que ele defende é o da necessidade de ressignificação das relações sociais em prol do estabelecimento de ações solidárias não meramente pontuais em tempos de pandemia, mas que possam ser cristalizadas como um novo horizonte das relações intersubjetivas.

\section{A abordagem biopolítica de Agamben acerca da Covid-19}

Antes de apresentar a posição de Agamben acerca da epidemia da Covid-19, para que os conceitos não sejam postos abruptamente, explicitarei de modo muito breve - haja vista isso não ser o meu ponto neste artigo - o que o autor entende por "biopolítica", já que este é o conceito precípuo mediante o qual se efetua a leitura agambeniana dos efeitos e das entrelinhas da epidemia supracitada.

Do ponto de vista teórico, a biopolítica de Agamben inicialmente busca referências em Foucault, mormente, na tese de $A$ Vontade de saber ${ }^{2}$ segundo a qual - na interpretação de Agamben - no limiar da modernidade a vida natural teria sido incluída nos mecanismos e nos cálculos do poder estatal e, com isso, a política teria se tornado "biopolítica"3.

As técnicas de controle e de normatização da vida nua pelo poder soberano é um ponto central nessa nova configuração política. Como escreve o próprio Agamben, "o ingresso da zoé na esfera da pólis, a politização da vida nua como tal, constitui o evento decisivo da modernidade, que assinala a transformação radical das categorias político-filosóficas do pensamento clássico" "4.

A "vida nua" é vida matável, manipulável pelas técnicas de dominação do poder soberano que decide o estado de exceção (auctoritas, non veritas facit legem). Ela é "sacer" no sentido latino de sagrada, mas também no sentido de sacrificada. Desse modo, indo além de Foucault, Agamben entende que mais do que um evento moderno, a "vida nua" constitui o primeiro paradigma do espaço político do Ocidente.

\footnotetext{
2 "Por milênios o homem permaneceu o que era para Aristóteles: um animal vivente e, além disso, capaz de existência política; o homem moderno é um animal em cuja política está em questão a sua vida de ser vivente”. FOUCAULT. Histoire de la sexualité : La volonté de savoir, p. 127.

${ }^{3}$ AGAMBEN. Homo Sacer: o poder soberano e a vida nua, p. 11.

${ }^{4}$ AGAMBEN. Homo Sacer: o poder soberano e a vida nua, p. 12.
} 
A tese foucaultiana deverá, então, ser corrigida ou, pelo menos, integrada, no sentido de que aquilo que caracteriza a política moderna não é tanto a inclusão da zoé na pólis, em si antiguíssima, nem simplesmente o fato de que a vida como tal venha a ser um objeto eminente dos cálculos e das previsões do poder estatal; decisivo é, sobretudo, o fato de que, lado a lado com o processo pelo qual a exceção se torna em todos os lugares a regra, o espaço da vida nua, situado originalmente à margem do ordenamento, vem progressivamente coincidir com o espaço político, e exclusão e inclusão, externo e interno, bíos e zoé, direito e fato entram em uma zona de irredutível indistinção ${ }^{5}$.

Postas essas poucas elucidações conceituais em torno da "biopolítica", centrar-me-ei no objetivo deste artigo que consiste em apresentar as abordagens mais atuais dos autores aqui propostos acerca da Covid-19, recolhendo mormente suas teses fundamentais a partir de entrevistas ocorridas recentemente nos meses de fevereiro, março e abril deste ano.

No seu artigo "A invenção de uma epidemia" (L’invenzione di un'epidemia), publicado em 26 de fevereiro de 2020 no site da editora Quodlibet, Agamben chamou de "desproporcional" e de "irracionais e completamente injustificadas" as medidas emergenciais das autoridades italianas e a pressão midiática na tentativa de fazer com que o povo ficasse em quarentena e em isolamento social. Eu penso que possivelmente Agamben errou seu diagnóstico tomando por base sua ideia de que tudo é biopoder, estado de exceção e limitação do indivíduo a partir do controle estatal. Errou drasticamente porque a Itália, com mais de 23 mil mortos e mais de 178 mil casos de infecção por coronavírus, é um dos países que mais sofre no mundo com a letalidade da Covid- $19^{6}$.

$\mathrm{Na}$ análise de Agamben o Estado, em parceria com a mídia, tentou incutir nos cidadãos italianos o temor do contágio como uma forma de restringir liberdades por meio de medidas profiláticas de isolamento social. Ou seja, a "epidemia" - que sabemos que depois tornou-se uma forte pandemia - seria um mecanismo ideológico de controle. Agamben, desse modo, desprezou os impactos biológicos do vírus e apressou-se em tirar conclusões parciais e enviesadas da Covid-19, incorrendo numa simplificação de algo complexo, haja vista seus impactos lesivos por meio de infeções rigorosas causar milhares de mortes no mundo.

No início do artigo supracitado, Agamben usa dados projetivos do Conselho Nacional de Pesquisa - Consiglio Nazionale delle Ricerche (CNR) - segundo os quais 10 a 15\% dos infectados na Itália desenvolveriam quadro pneumológico, e destes, em torno de $4 \%$ demandariam cuidados em Centros de Terapia Intensiva (CTIs). Diante disso ele questiona se, caso a situação seja essa mesma, "por que os meios de comunicação e as autoridades se esforçam por difundir um clima de pânico, provocando um verdadeiro estado de exceção, com graves limitações dos movimentos e uma suspenção do funcionamento normal das condições de vida e de trabalho em regiões inteiras?"7.

Diante das projeções apontadas pela CNR, Agamben considera "desproporcionais" medidas de quarentena e de isolamento social que privem os indivíduos de exercer suas liberdades. São demasiadas as restrições que mandam fechar escolas, fronteiras, museus etc. $\mathrm{Na}$ sua análise, neste artigo de 26 de fevereiro de 2020, tais medidas via decreto se devem a dois fatores: (i) elas efetivam uma tendência crescente de autoridades políticas em utilizar o estado de exceção como paradigma normal do governo, como uma forma de exercer o poder e domínio legal sobre a vida dos indivíduos por meio da vigilância ativa e da penalização de transgressões de regras de quarentena; (ii) as medidas efetivam um estado de pânico coletivo que legitimam a restrição da liberdade em troca de presumível segurança e ordem.

Em 16 de março de 2020, Agamben escreve novamente na Quodlibet um texto intitulado "Contágio", em que ele continua com a mesma tese segundo a qual o governo teria criado um estado de medo coletivo a fim de instituir um estado de exceção. "Uma das consequências mais desumanas do pânico que se busca por todos os meios propagar na Itália durante a chamada

\footnotetext{
${ }^{5}$ AGAMBEN. Homo Sacer: o poder soberano e a vida nua, p. 16.

${ }^{6}$ https://gisanddata.maps.arcgis.com/apps/opsdashboard/index.html\#/bda7594740fd40299423467b48e9ecf6

7 AGAMBEN. L'invenzione di un'epidemia.
} 
epidemia do coronavírus é a própria ideia de contágio que está na base das medidas excepcionais de emergência adotadas pelo governo" 8 .

O autor entende que a disseminação da ideia de "contágio" fez com que cada cidadão italiano não apenas adotasse as regras de isolamento e restrição, como também se tornasse um censor e vigia pronto a punir os que transgredissem as normas de exceção impostas pelas autoridades por meio de decretos e sem a mínima discussão e aquiescência do parlamento.

As restrições de liberdades e o isolamento social provocaram, segundo Agamben, algo pior que é a "degeneração das relações". O distanciamento calculado em metros, o contato apenas virtual, o isolamento, reforçaram o declínio das relações sociais e a "abolição do próximo" ( $i l$ nostro prossimo è stato abolito). O contágio e o estado de exceção criaram aquilo que os governos buscam efetivar há tempos:

[...] que as universidades e as escolas se fecham de uma vez por todas e que as aulas sejam dadas apenas online, que deixemos de nos reunir e falar por questões políticas ou culturais, e que apenas possamos trocar mensagens digitais, que na medida do possível as máquinas substituam todo o contato - todo contágio - entre os seres humanos ${ }^{9}$.

Um terceiro texto de Agamben na Quodlibet sobre o assunto veio em 27 de março de 2020, intitulado "Reflexões sobre a peste" (Riflessioni sulla peste). O autor inicia afirmando que o texto não é propriamente sobre a "epidemia", mas sobre as relações humanas, especificamente, sobre como as pessoas aceitaram as regras restritivas de isolamento social sem questioná-las, isto é, como aceitaram suspender as condições normais da vida, suas relações de trabalho, amizade, amor, crenças, etc., sem interpela-las. A sua hipótese é que na verdade o mundo já estava tendente a incorporar o isolamento e a exceção.

Eu penso que Agamben pode ter razão no que diz respeito à sua crítica ao individualismo e aos abusos do Estado em muitos aspectos, mas no que concerne à sua leitura acerca dos impactos da pandemia do coronavírus, ele tem limitações. A sua obsessão ao interpretar restrições como imposição de estado de exceção oblitera, a meu ver, uma situação emergencial de saúde pública em que comprovadamente morreram mais de 23 mil pessoas na Itália infectadas pela Covid-19. Em nível mundial, hoje 20 de abril de 2020, este número já supera o total de 166 mil mortos ${ }^{10}$.

Agamben não vislumbra adequadamente o fator biológico da existência da vida para além do conceito de "exceção"; ele apenas o entende sob o invólucro da "vida nua" enquanto vida capturável pelo poder soberano. A sua leitura se restringe a entender a manutenção da vida como uma presa fácil do poder soberano, uma leitura ainda presa ao modelo do Leviatã de Hobbes. Além disso, ele parece ignorar não apenas o número de mortes na Itália e no mundo, como também reforça o discurso neoliberal de relaxamento da quarentena e do isolamento social, sendo que no apelo neoliberal subjaz o mantra que a produção não pode parar (que é a mesma justificativa de Bolsonaro e seguidores no Brasil), e no mantra da leitura biopolítica agambeniana da pandemia que o isolamento é uma invenção do Estado para legitimar medidas restritivas de exceção da liberdade.

Agamben não endossa o sentido profilático da quarentena e do isolamento social demandado pela Organização Mundial da Saúde que toma por base dados fáticos e científicos, e não vê a adesão às regras de isolamento como um ato solidário de respeito à vida individual e coletiva. A sua lente de leitura da pandemia sob um enfoque meramente biopolítico baseado no conceito de "estado de exceção", turva e encobre a possibilidade de enxergar potenciais de solidariedade e de rebelião ao sistema econômico-político dominante em pleno "isolamento social".

Isso é ratificado no texto de 06 de abril de 2020, intitulado "Distanciamento social", em que Agamben perscruta as bases políticas do novo léxico político do "distanziamento sociale" materializado em estratégias de "confinamento".

\footnotetext{
${ }^{8}$ AGAMBEN. Contagio.

${ }^{9}$ AGAMBEN. Contagio.

${ }^{10}$ https://covid19.who.int/
} 
Embora existam, como acontece sempre, os tolos que sugerem que essa situação certamente pode ser considerada positiva e que as novas tecnologias digitais há muito tempo permitem que as pessoas se comuniquem felizes à distância, não acredito que uma comunidade fundada em 'distanciamento social' humana e politicamente viável ${ }^{11}$.

Para o autor política se faz com interação, proximidade e vivências concretas. O distanciamento social, o confinamento, não mais é que a ruptura da comunidade política. O pânico coletivo instaurou o confinamento e com ele a massificação e a passividade dos confinados à espera de um líder que decrete e dê ordens acerca de seu fim.

Nisso Agamben tem razão, porém, o esvaziamento da vida política já ocorria antes da pandemia. Agora ele apenas ganhou uma legitimidade técnica por questões de saúde pública. Ou seja, o desafio da reconstrução da vida política é uma constante, e o seu confronto deve também ser permanente. O individualismo moderno liberal arrasta-se a séculos invadindo as múltiplas esferas da vida, portanto, não é um produto exclusivo de profilaxia de "isolamento social".

O texto mais recente de Agamben que acessei sobre as implicações da "epidemia" do coronavírus foi "Una domanda" (Uma pergunta), escrito em 13 de abril de 2020. Ele questiona como a Itália não percebeu o colapso ético e político diante da epidemia. No seu entendimento, a ciência moderna criou uma ruptura entre o biológico e o político de modo que a partir do "contágio" levou as pessoas a se preocupar estritamente com a primeira dimensão em detrimento da segunda e de demais dimensões da vida. A medicina passou a ter a última palavra, e as pessoas passaram facilmente a se sujeitar a mecanismos de higienização social impostas por autoridades.

Aceitamos sem criar muitos problemas, apenas em nome de um risco que não podia ser especificado, para limitar a uma extensão que nunca havia acontecido antes na história do país, mesmo durante as duas guerras mundiais (o toque de recolher durante a guerra foi limitado a determinadas horas) nossa liberdade de movimento. Consequentemente, aceitamos, apenas em nome de um risco que não podia ser especificado, suspender efetivamente nossos relacionamentos de amizade e amor, porque nosso vizinho havia se tornado uma possível fonte de contágio ${ }^{12}$.

Agamben entende que o "distanciamento social", um eufemismo para um verdadeiro "isolamento" e deterioração das relações concretas, tornou-se o novo princípio de organização da sociedade. Eu penso que a sua análise é válida num quesito, mas problemática noutro: é válida no sentido que põe em questão a deterioração das relações éticas e políticas, que não é um problema tipicamente italiano, mas global; é falha porque que ignora os riscos letais do vírus. Relaxar regras de quarentena e de distanciamento social em tempos de pandemia implica assumir o risco de exporse ao caos público na saúde e de se ter milhares de mortes, em especial, de pessoas marginalizadas que não têm acesso aos direitos básicos.

No mesmo texto de 13 de abril de 2020, Agamben faz duas críticas mais concretas, uma ao Papa Francisco e uma outra aos juristas. Quanto ao Papa, escreve:

A Igreja, sob um papa chamado Francisco, esqueceu que Francisco abraçava leprosos. Ele esqueceu que uma das obras de misericórdia é visitar os doentes. Ele esqueceu que os mártires ensinam que é preciso estar disposto a sacrificar a vida em vez da fé e que desistir do próximo significa desistir da fé ${ }^{13}$.

Essa afirmação demonstra que Agamben, por um lado, ignora ou desconhece as ações solidárias do Papa Francisco e, por outro lado, continua reticente quanto à letalidade da Covid-19; continua com reflexões parciais e enviesadas centradas apenas no aspecto biopolítico da epidemia. Ele oblitera de sua reflexão os aspectos biológicos relativos à saúde da população. Dá a entender

\footnotetext{
${ }^{11}$ AGAMBEN. distanziamento sociale.

${ }^{12}$ AGAMBEN, Una domanda

${ }^{13}$ AGAMBEN. distanziamento sociale.
} 
que um ato correto e legítimo de rebeldia seria o de transgredir as regras preconizadas pela Organização Mundial da Saúde.

A outra crítica de Agamben é endereçada aos juristas que, segundo ele, têm sido omissos ao não questionar a legitimidade constitucional dos decretos de exceção:

Todos os limites foram excedidos e temos a impressão de que as palavras do primeiro ministro e do chefe da proteção civil têm, como foi dito para as do Führer, valor imediatamente legal. E não está claro como, uma vez esgotado o limite de validade temporal dos decretos de urgência, as limitações da liberdade, como anunciadas, serão mantidas. Com que arranjos legais? Com um estado de exceção permanente? É dever dos juristas verificar se as regras da constituição são respeitadas, mas os juristas estão calados ${ }^{14}$.

Quanto a isso, de acordo. A vigilância do cumprimento constitucional em países democráticos é um dever da suprema corte e jamais deve cessar. Na verdade, não apenas da suprema corte, mas um dever cívico dos cidadãos, das instituições e da sociedade civil como um todo. Passarei agora a analisar a entrevista de Habermas sobre as implicações ético-políticas da pandemia do coronavírus sob o enfoque normativo dos direitos humanos, apresentando assim, conforme proposto inicialmente, uma leitura alternativa com o objetivo de ampliar as abordagens para além do espectro biopolítico.

\section{Habermas: as implicações ético-políticas da pandemia do coronavírus e a centralidade normativa dos direitos humanos}

O fio condutor destas reflexões no que diz respeito ao seu amparo normativo concerne a uma articulação entre dignidade humana, direitos humanos e Estado democrático de direito e como essa vinculação normativa é usada por Habermas para analisar o problema da Covid-19. No ensaio "Sobre a constituição da Europa", Habermas defende a tese que a dignidade humana é a fonte dos direitos humanos (die Menschenwürde ist die normative Quelle der Menschenrechte), e que isso constitui a base normativa de legitimidade das democracias. A violação dos direitos humanos implica a violação da própria democracia.

A dignidade humana, que é uma e a mesma em todo lugar e para cada um, fundamenta a indivisibilidade dos direitos fundamentais. [...]. A dignidade humana é um sismógrafo que mostra o que é constitutivo para uma ordem jurídica democrática [...]. A dignidade humana forma algo como o portal por meio do qual o conteúdo igualitário-universalista da moral é importado ao direito. A ideia de dignidade humana é a dobradiça conceitual que conecta a moral do respeito igual por cada um com o direito positivo e com a legislação democrática ${ }^{15}$.

Numa entrevista concedida ao jornalista francês Nicolas Truong, publicada no Le Mond em 10 de abril de 2020, reproduzida no Brasil pelo Instituto Humanitas da Unisinos, Habermas analisa algumas implicações éticas e políticas da pandemia do coronavírus.

Inicialmente, o filósofo salienta que o vírus da COVID-19, coloca o mundo num patamar de incertezas, mesmo em se tratando de experts infectologistas, virologistas, e agentes públicos de saúde. Há um caldeirão de opiniões com fluxos constantes nas redes sociais, prós e contras a manutenção de quarentena, posicionamentos da sociedade civil perante medidas políticas, especulações acerca de possíveis vacinas para a cura, mas tudo num campo de incertezas epistêmicas, num campo movediço que permeia os debates no mundo virtual.

Além das incertezas diante da crise sanitária global, como dito, Habermas pontua algumas implicações éticas e políticas da pandemia do coronavírus. Na esfera ética, ele evoca a Constituição

\footnotetext{
${ }^{14}$ AGAMBEN. distanziamento sociale.

${ }^{15}$ HABERMAS. Sobre a constituição da Europa, p. 16-17.
} 
Alemã, ou melhor dizendo, a septuagenária Lei Fundamental da República Federal da Alemanha (Grundgetz für die Bundsrepublik Deutschland) outorgada e promulgada no pós-guerra em 1949. O ponto de sustentação jurídica para a proteção ética orbita em torno dos direitos humanos, concretamente, da dignidade da pessoa humana.

A dignidade humana é indisponível, intangível, e não pode ser desrespeitada, mas, pelo contrário, é um dever do poder público respeitá-la e protegê-la. Conforme o Art. 2 da Lei Fundamental supracitada, "todos têm o direito à vida e à integridade física" (Jeder hat das Recht auf Leben und körperliche Unversehrtheit). Posta essa base normativa constitucional, Habermas elenca os desafios éticos oriundos da crise pandêmica, a saber: (i) o problema da triagem, (ii) e o momento correto para a interrupção do distanciamento social.

O problema da triagem diz respeito a casos difíceis (hard cases), porém suscetíveis de ocorrer devido a superlotação e a escassez de unidades de terapia intensiva (UTIs), em que médicos devem fazer a dura escolha acerca de quem deve viver e de quem deve morrer, um dilema bioético forte, que em todo caso implica a perda de vida de um paciente ou de outro. Desse modo, as proteções normativas constitucionais em favor da vida esbarram concretamente em casos graves, mormente, diante da falta de aparelhos respiratórios para manter indivíduos vivos.

Trata-se de uma luta biológica pela sobrevivência; no plano ético, o médico sabe prima facie que os indivíduos têm direitos iguais e que nenhuma vida pode ser colocada em contraposição à outra, mas em caso de necessidade extrema, o critério biológico é invocado como mediador da decisão: na prática, "em situações que obrigam a tomar decisões trágicas, o médico deve ser orientado exclusivamente pelas disposições sanitárias relativas à maior perspectiva de sucesso do tratamento clínico"16.

Isso constitui um verdadeiro cenário de guerra em que o número de doentes excede consideravelmente o número de leitos. Tal cenário, por exemplo, já ocorreu na Itália assolada com inúmeros casos de coronavírus. Hoje, 20 de abril de 2020, já são ao todo na Itália 178,972 casos de Covid-19, sendo 26,660 mortes. O adeus de pacientes terminais aos seus familiares, por medidas profiláticas, é dado por meio de acesso remoto em que, comumente, o agente de saúde segura um tablet enquanto parentes estabelecem um último contato.

Um outro desafio ético visto por Habermas, como dito, é relativo ao momento correto para a interrupção do distanciamento social. Ele inicialmente pergunta se teríamos que aceitar o risco de sobrecarregar os sistemas de saúde a ponto de aumentar a taxa de mortalidade para reiniciar mais cedo a economia. Caso se ceda às demandas do mercado, qual seria o saldo em termos biológicos de manutenção da vida e em termos éticos de não violação de direitos humanos? Quem lucra com a interrupção do distanciamento social e com o fim da quarentena?

A resposta de Habermas é que "os políticos devem resistir à 'tentação utilitarista' de pesar os danos econômicos ou sociais, por um lado, e as mortes evitáveis, pelo outro"17. Há uma pressão liberal para que a produção e o lucro não parem, e tudo continue em ritmo acelerado, mas há, em sentido oposto, uma demanda prática e vital de desaceleração em prol da manutenção da vida, mesmo que isso cause período longo de recessão econômica.

Habermas aqui segue o apelo da moralidade de $\mathrm{Kant}^{18}$ segundo o qual a vida não tem preço, e que o indivíduo não deve ser coisificável, não deve ser tratado simplesmente como meio, mas como fim em si mesmo; algo também encontrado no imperativo hegeliano do direito abstrato segundo o qual "sê uma pessoa e respeita os outros enquanto pessoas"19.

Além das implicações éticas, Habermas também pontua implicações políticas oriundas da crise pandêmica do coronavírus. Sua proposta é que o Estado, ao invés de simplesmente ceder às demandas neoliberais, deve resguardar os direitos fundamentais das pessoas, tendo como premissa a

16 https://www.lemonde.fr/idees/article/2020/04/10/jurgen-habermas-dans-cette-crise-il-nous-faut-agir-dans-le-savoirexplicite-de-notre-non-savoir_60361783232.html

17 https://www.lemonde.fr/idees/article/2020/04/10/jurgen-habermas-dans-cette-crise-il-nous-faut-agir-dans-le-savoirexplicite-de-notre-non-savoir 60361783232.html

${ }^{18}$ KANT. Fundamentação da metafísica dos costumes.

${ }^{19}$ HEGEL. Linhas fundamentais da filosofia do direito, ou direito natural e ciência do Estado em compêndio, § 36. 
proibição de decisões que aceitem a possibilidade de morte de indivíduos. A vida não pode estar disponível a investidas negacionistas do mercado, e cumpre ao Estado democrático de direito a afirmação da vida e a implementação de direitos sociais a fim de assistir em especial aos mais impactados economicamente pela pandemia.

A situação emergencial legitima o Estado, por questões de saúde pública, como medida excepcional, a impor determinados limites aos cidadãos, como por exemplo, sanções para quem desrespeita medidas profiláticas de isolamento social durante o ápice de transmissão da Covid-19. A medida política se dá em virtude da exigência do direito primário à proteção da vida e à integridade física $^{20}$.

Ao fim da entrevista, Habermas ainda salienta três pontos: que a pandemia traz a possibilidade de uma luta pela supressão de uma política mundial dominada pelo neoliberalismo; o cuidado para que a fragilidade mundial diante da pandemia não legitime o reaparecimento e o fortalecimento de pensamentos extremistas de direita a partir de um populismo interposto como o salvador da pátria; e, como conclusão, ele propõe que o "choque", o impacto do coronavírus, gere a possibilidade de modos de vida e agir solidários.

\section{Considerações finais}

Aqui no Brasil, o presidente Bolsonaro tem adotado uma postura de relativização da Covid19, afirmando que seria uma "gripezinha", e opondo-se a medidas de isolamento social, sob a argumentação que isso prejudicaria a economia do país. Travou-se, assim, uma queda de braço entre o Ministério da Saúde e o Governo, o que progressivamente gerou um quadro de instabilidade institucional e de desentendimento na gestão da crise sanitária diante da pandemia do coronavírus, algo que resultou na demissão do ministro da saúde.

O que inicialmente era uma relativização ou minimização do presidente ganhou ares públicos e repercussão internacional de negacionismo, o que o torna um dos piores líderes mundiais na gestão da crise, desrespeitando não apenas orientações sanitárias do seu ex-ministro, como também preconizações e protocolos técnicos da Organização Mundial da Saúde (OMS), colocando a população em risco.

Eu penso que a alternativa de Habermas de consideração dos impactos ético-políticos da Covid-19 a partir de um horizonte normativo de proteção da vida e de sua irredutibilidade a processos econômicos e mercadológicos, é uma leitura bastante adequada para a nossa conjuntura. A leitura biopolítica de Agamben também é relevante, sobretudo, à medida que evoca a necessidade permanente de vigilância da parte de órgãos jurídicos (daí a sua crítica à omissão do judiciário na Itália) e de cidadãos a fím de que não se permita a decretação de um estado de exceção como situação de normalidade que viole liberdades e que capture a vida e a transforme em mera "vida nua". Porém, uma leitura biopolítica padece de restrições no sentido que, por um lado, prescinde da dimensão biológica da letalidade do vírus e de informações técnicas e científicas da Organização Mundial da Saúde, e, por outro lado, não vê no conjunto de medidas profiláticas de isolamento social o ganho da incolumidade e o potencial de ressignificação de cosmovisões e de posturas com vistas a instauração de uma nova ordem crítica do individualismo e crítica do projeto neoliberal.

Não se trata aqui de escolher uma leitura em detrimento de outra no seu todo, mas penso que Habermas avança no diagnóstico normativo no sentido que salvaguarda os direitos humanos e ao mesmo tempo defende a tese que a vida não pode estar disponível a investidas negacionistas do mercado e, ipso facto, cumpre ao Estado democrático de direito a afirmação da vida e a implementação de direitos sociais a fim de assistir em especial aos mais impactados economicamente pela pandemia da Covid-19.

20 https://www.lemonde.fr/idees/article/2020/04/10/jurgen-habermas-dans-cette-crise-il-nous-faut-agir-dans-le-savoirexplicite-de-notre-non-savoir_60361783232.html 


\section{Referências}

AGAMBEN, G. L'invenzione di un'epidemia. Publicado em 26 de fevereiro de 2020 no sítio da Editora Quodlibet.it. Disponível em: <https://www.quodlibet.it/giorgio-agamben-l-invenzione-diun-epidemia>. Acesso em: 15 de abril de 2020.

AGAMBEN, G. Contagio. Publicado em 11 de março de 2020 no sítio da Editora Quodlibet.it. Disponível em: 〈https://www.quodlibet.it/giorgio-agamben-contagio >. Acesso em: 15 de abril de 2020.

AGAMBEN, G. Riflessioni sulla peste. Publicado em 27 de março de 2020 no sítio da Editora Quodlibet.it. Disponível em: 〈https://www.quodlibet.it/giorgio-agamben-riflessioni-sulla-peste>. Acesso em: 15 de abril de 2020.

AGAMBEN, G. distanziamento sociale. Publicado em 06 de abril de 2020 no sítio da Editora Quodlibet.it. Disponível em: 〈https://www.quodlibet.it/giorgio-agamben-distanziamento-sociale>. Acesso em: 16 de abril de 2020.

AGAMBEN, G. Una domanda. Publicado em 13 de abril de 2020 no sítio da Editora Quodlibet.it. Disponível em: 〈https://www.quodlibet.it/giorgio-agamben-una-domanda>. Acesso em 16 de abril de 2020.

AGAMBEN, G. Homo Sacer: o poder soberano e a vida nua I. Trad. Henrique Burigo. Belo Horizonte: Editora da UFMG, 2002.

AGAMBEN, G; BUTLER, Judith; HARVEY, David et al. Sopa de Wuhan. Pensamiento Contemporáneo en tiempos de pandemia. Pablo Amadeo e Editorial Social Preventivo e Obligatorio (ASPO). 2020.

DOHERTY, P. Pandemics: What everyone needs to know. New York: Oxford University Press, 2013.

FOUCAULT, M. Histoire de la sexualité : La volonté de savoir. Paris : Gallimard, 1976.

Grundgetz für die Bundsrepublik Deutschland. < https://www.gesetze-iminternet.de/gg/BJNR000010949.html>. Acesso em: 13 de abril de 2020.

HABERMAS, J. Entrevista sobre implicações éticas e políticas do coronavírus. Entrevistado por Nicolas Truong. Disponível em: <https://www.lemonde.fr/idees/article/2020/04/10/jurgenhabermas-dans-cette-crise-il-nous-faut-agir-dans-le-savoir-explicite-de-notre-non-

savoir_60361783232.html>. Acesso em 13: de abril de 2020. Reprodução, in: Instituto Humanitas da Unisinos: <http://www.ihu.unisinos.br/597983-a-solidariedade-e-a-unica-cura-entrevista-comjuergen-habermas >. Acesso em: 13 de abril de 2020.

HABERMAS, J. Sobre a constituição Europa: um ensaio. Trad. Denilson Werle, Luiz Repa, Rúrion Melo. Editora Unesp, 2012.

HEGEL, G W F. Linhas fundamentais da filosofia do direito, ou direito natural e ciência do Estado em compêndio. Trad. Paulo Meneses [et al.]. São Leopoldo, RS: Ed. UNISINOS, 2010.

HOBBES, T. Leviatã ou matéria, forma e poder de uma república eclesiástica e civil. Trad. João Paulo Monteiro, Maria Beatriz Nizza da Silva, Claudia Berliner. São Paulo: Martins Fontes, 2003.

KANT, I. Fundamentação da metafísica dos costumes. Trad. Paulo Quintela. São Paulo: Abril Cultural, 1974.

World Health Organization. <https://covid19.who.int/>Acesso em: 20 de abril de 2020. 